\title{
Dipeptidyl-peptidase-4 as a marker of activated fibroblasts and a potential target for the treatment of fibrosis in Systemic Sclerosis
}

Soare, Alina ; Györfi, Hermina A ; Matei, Alexandru E ; Dees, Clara ; Rauber, Simon ; Wohlfahrt, Thomas ; Chen, Chih-Wei ; Ludolph, Ingo ; Horch, Raymund E ; Bäuerle, Tobias ; von Hörsten, Stephan ; Mihai, Carina ; Distler,

Oliver ; Ramming, Andreas ; Schett, Georg ; Distler, Jörg H W

\begin{abstract}
BACKGROUND: Dipeptidyl-peptidase-4 (DPP4) identifies a dermal fibroblast lineage involved in scaring during wound healing. The role of DDP4 in tissue fibrosis, however, is unknown. The aim of the present study was to evaluate DPP4 as a potential target for the treatment of fibrosis in systemic sclerosis (SSc). METHODS: The expression of DPP4 was analyzed by real-time PCR, immunofluorescence and Western blot. The activity of DPP4 was modulated by overexpression, knockdown and pharmacological inhibition using Sitagliptin and Vildagliptin. The effects of DPP4 inhibition were analyzed in human dermal fibroblasts and in different mouse models of SSc $(n=6)$. RESULTS: The expression of DPP4 and the number of DPP4 positive fibroblasts were increased in fibrotic skin of SSc patients in a TGF- $\beta$ dependent manner. DPP4 positive fibroblasts expressed higher levels of myofibroblast markers and collagen $(\mathrm{p}<0.001)$. Overexpression of DPP4 promoted fibroblast activation, whereas pharmacological or genetic inactivation of DPP4 reduced proliferation, migration, expression of contractile proteins and release of collagen by interfering with TGF- $\beta$-induced ERK signaling $(\mathrm{p}<0.001)$. DPP4knockout mice were less sensitive to bleomycin-induced dermal and pulmonary fibrosis $(\mathrm{p}<0.0001)$. Treatment with DPP4 inhibitors promoted regression of fibrosis induced by bleomycin- or chronic graft-versus-host disease and ameliorated fibrosis in TSK1 mice $(\mathrm{p}<0.001)$. The antifibrotic effects were associated with reduced inflammation. CONCLUSION: DPP4 characterizes a population of activated fibroblasts and regulates TGF- $\beta$-induced fibroblast activation. Inhibition of DPP4 exerts potent anti-fibrotic effects in well tolerated doses. These results may have direct translational implications as DPP4 inhibitors are already in clinical use for diabetes. This article is protected by copyright. All rights reserved.
\end{abstract}

DOI: https://doi.org/10.1002/art.41058

Posted at the Zurich Open Repository and Archive, University of Zurich

ZORA URL: https://doi.org/10.5167/uzh-172739

Journal Article

Accepted Version

Originally published at:

Soare, Alina; Györfi, Hermina A; Matei, Alexandru E; Dees, Clara; Rauber, Simon; Wohlfahrt, Thomas; Chen, Chih-Wei; Ludolph, Ingo; Horch, Raymund E; Bäuerle, Tobias; von Hörsten, Stephan; Mihai, Carina; Distler, Oliver; Ramming, Andreas; Schett, Georg; Distler, Jörg H W (2020). Dipeptidyl-peptidase-4 as a marker of activated fibroblasts and a potential target for the treatment of fibrosis in Systemic Sclerosis. Arthritis and Rheumatology, 72(1):137-149.

DOI: https://doi.org/10.1002/art.41058 
DR. ALINA SOARE (Orcid ID : 0000-0002-3881-2325)

DR. ALEXANDRU-EMIL EMIL MATEI (Orcid ID : 0000-0003-1248-3145)

DR. OLIVER DISTLER (Orcid ID : 0000-0002-2413-1959)

PROF. GEORG SCHETT (Orcid ID : 0000-0001-8740-9615)

DR. JÖRG H.W. DISTLER (Orcid ID : 0000-0001-7408-9333)

Article type : Full Length

\section{Dipeptidyl-peptidase-4 as a marker of activated fibroblasts and a potential target for} the treatment of fibrosis in Systemic Sclerosis

Running Title: Dipeptidyl-peptidase-4 in SSc

Alina Soare, MD ${ }^{1,2}$, Hermina A. Györfi, MD ${ }^{1}$, Alexandru E. Matei, MD ${ }^{1}$, Clara Dees, PhD ${ }^{1}$, Simon Rauber, $\mathrm{PhD}{ }^{1}$, Thomas Wohlfahrt, $\mathrm{PhD}{ }^{1}$, Chih-Wei Chen, $\mathrm{PhD}{ }^{1}$, Ingo Ludolph, MD ${ }^{3}$, Raymund E. Horch, $\mathrm{MD}^{3}$, Tobias Bäuerle, $\mathrm{MD}^{4}$, Stephan von Hörsten, MD ${ }^{5}$, Carina Mihai, MD ${ }^{6,2}$, Oliver Distler, MD ${ }^{6}$, Andreas Ramming, MD ${ }^{1}$, Georg Schett, MD ${ }^{1}$, Jörg H.W. Distler, MD ${ }^{1 *}$

${ }^{1}$ Department of Internal Medicine 3 - Rheumatology and Immunology, Friedrich-AlexanderUniversity (FAU) Erlangen-Nürnberg and Universitätsklinikum Erlangen, Erlangen, Germany, ${ }^{2}$ Carol Davila University of Medicine and Pharmacy Bucharest, Romania, ${ }^{3}$ Department of Plastic and Hand Surgery and Laboratory for Tissue Engineering and Regenerative Medicine, Friedrich-Alexander-University (FAU) Erlangen-Nürnberg and Universitätsklinikum Erlangen, Erlangen, Germany, ${ }^{4}$ Institute of Radiology, Preclinical Imaging Platform Erlangen, Friedrich-Alexander-University (FAU) Erlangen-Nürnberg Erlangen, Germany, ${ }^{5}$ Department of Experimental Therapy, Friedrich-Alexander-University

This article has been accepted for publication and undergone full peer review but has not been through the copyediting, typesetting, pagination and proofreading process, which may lead to differences between this version and the Version of Record. Please cite this article as doi: 10.1002/art.41058

This article is protected by copyright. All rights reserved. 
(FAU) Erlangen-Nürnberg and Universitätsklinikum Erlangen, Erlangen, Germany, ${ }^{6}$ Division of Rheumatology, University Hospital Zurich, Zurich, Switzerland.

Corresponding author: Jörg H. W. Distler, MD; Department of Internal Medicine 3 and Institute for Clinical Immunology, University of Erlangen-Nuremberg, Ulmenweg 18, 91054 Erlangen, Germany, Tel.: +49 9131 43008, FAX: +49 9131 35467, Email: joerg.distler@ukerlangen.de

\section{GRANT SUPPORT}

Grants SO 1735/2-1, DI 1537/7-1, DI 1537/8-1, DI 1537/9-1, DI 1537/9-2, DI 1537/11-1, DI 1537/12-1, DI 1537/13-1, DI 1537/14-1, DE 2414/2-1, DE 2414/4-1 and RA 2506/3-1 of the German Research Foundation, SFB CRC1181 (project C01) and SFB TR221 (B04) of the German Research Foundation, grants 17-11-20-1- Soare and 16-10-05-1-Ramming of the ELAN-Foundation Erlangen, grants J40 and A64 of the IZKF in Erlangen, grant 2013.056.1 of the Wilhelm-Sander-Foundation, grants 2014_A47 and 2014_A184 of the Else-KrönerFresenius-Foundation.

\section{COMPETING INTERESTS}

OD has consultancy relationships and/or has received research funding from Actelion, Pfizer, Ergonex, BMS, Sanofi-Aventis, United BioSource Corporation, Roche/Genentech, Medac, Biovitrium, Boehringer Ingelheim, Novartis, 4D Science, Active Biotech, Bayer, Sinoxa, Serodapharm, EpiPharm, GSK, Pharmacyclics and Biogen $(<\$ 10.000)$.

JHWD has consultancy relationships with Actelion, Active Biotech, Anamar, Bayer Pharma, Boehringer Ingelheim, Celgene, Galapagos, GSK, Inventiva, JB Therapeutics, Medac, Pfizer, RuiYi and UCB. JHWD has received research funding from Anamar, Active Biotech, Array 
Biopharma, BMS, Bayer Pharma, Boehringer Ingelheim, Celgene, GSK, Novartis, SanofiAventis and UCB $(<\$ 10.000)$. JHWD is stock owner of 4D Science.

AS, HAG, AEM,CD, SR, TW, CWC, IL, REH, TB, SvH, CM, AR, GS: declare no competing financial interests

\section{Abstract}

Background: Dipeptidyl-peptidase-4 (DPP4) identifies a dermal fibroblast lineage involved in scaring during wound healing. The role of DDP4 in tissue fibrosis, however, is unknown. The aim of the present study was to evaluate DPP4 as a potential target for the treatment of fibrosis in systemic sclerosis (SSc).

Methods: The expression of DPP4 was analyzed by real-time PCR, immunofluorescence and Western blot. The activity of DPP4 was modulated by overexpression, knockdown and pharmacological inhibition using Sitagliptin and Vildagliptin. The effects of DPP4 inhibition were analyzed in human dermal fibroblasts and in different mouse models of SSc $(n=6)$.

Results: The expression of DPP4 and the number of DPP4 positive fibroblasts were increased in fibrotic skin of SSc patients in a TGF- $\beta$ dependent manner. DPP4 positive fibroblasts expressed higher levels of myofibroblast markers and collagen $(p<0.001)$. Overexpression of DPP4 promoted fibroblast activation, whereas pharmacological or genetic inactivation of DPP4 reduced proliferation, migration, expression of contractile proteins and release of collagen by interfering with TGF- $\beta$-induced ERK signaling $(p<0.001)$. DPP4knockout mice were less sensitive to bleomycin-induced dermal and pulmonary fibrosis $(\mathrm{p}<0.0001)$. Treatment with DPP4 inhibitors promoted regression of fibrosis induced by bleomycin- or chronic graft-versus-host disease and ameliorated fibrosis in TSK1 mice $(\mathrm{p}<0.001)$. The antifibrotic effects were associated with reduced inflammation. 
Conclusion: DPP4 characterizes a population of activated fibroblasts and regulates TGF- $\beta$ induced fibroblast activation. Inhibition of DPP4 exerts potent anti-fibrotic effects in well tolerated doses. These results may have direct translational implications as DPP4 inhibitors are already in clinical use for diabetes.

Systemic sclerosis ( $\mathrm{SSc}$ ) is a chronic fibrotic disease, that is associated with the highest case specific mortality of all connective tissue diseases (1). The central histopathologic hallmark of SSc is the uncontrolled and persistent activation of fibroblasts, which release excessive amounts of extracellular matrix (2). Fibroblasts are key effector cells in fibrotic diseases. Fibroblasts are, however, not a uniform population of cells, but compose of functionally and phenotypically different subsets. Emerging evidence highlights that chronic inflammatory diseases including rheumatoid arthritis are associated with dysbalances in the ratio of different fibroblast subsets and that those shifts may drive disease progression (3-7). The complexity of different fibroblast subsets in fibrotic diseases such as SSc is less well understood. However, it is well established that fibroblasts in fibrotic diseases can acquire an activated, so-called myofibroblast phenotype $(8,9)$. Although transforming growth factor $\beta$ (TGF- $\beta$ ) has emerged as a core pathway of fibroblast activation in SSc and in other fibrotic diseases, the molecular mechanisms underlying the persistent activation in fibroblasts remain incompletely understood (10).

Dipeptidyl-peptidase-4 (DPP4, also known as CD26) exists either as a type II transmembrane protein or as a soluble form $(11,12)$. DPP4 functions as serine protease that hydrolyses proline or alanine from the $\mathrm{N}$-terminus of a broad range of polypeptides $(13,14)$. DPP4 inactivates incretin hormones such as glucagon-like peptides or glucose-dependent insulinotropic peptide to inhibit insulin secretion and to promote diabetes mellitus. These findings have been successfully translated from bench-to-bedside and DPP4 inhibitors are 
currently widely used for the treatment of diabetes mellitus (15). However, the substrates of DPP4 are not restricted to incretin hormones, but include also a broad range of other soluble mediators such as chemokines. Moreover, DPP4 can modulate intracellular signaling not only via proteolytic cleavage of substrates, but also via direct interaction with key-regulatory molecules such as CD45 or adenosine deaminase, playing immune regulatory functions (16, 17). DPP4 has been playing a costimulatory role in $\mathrm{T}$ cells, to promote $\mathrm{T}$ - and $\mathrm{B}$ cell activation $(13,18)$. Treatment with DPP4 inhibitors lowered the incidence of autoimmune disorders in patients with diabetes mellitus (19). Of particular interest, Rinkevich and coworkers recently demonstrated that DPP4 expression identifies an embryonic fibroblast lineage with unique functions in wound healing (20). They demonstrated that DPP4expressing fibroblasts accounted for the bulk of connective tissue deposition upon surgical wounding. Inhibition of DPP4 reduced scaring without negatively affecting wound closure, suggesting that DPP4 inhibition may offer an avenue for selective targeting of a fibroblast population with high capacity of matrix production, while not affecting other populations with more homeostatic functions (20). However, the concept of a DPP4-expressing subpopulation of active, matrix-producing fibroblasts has not yet been translated and validated in the context of SSc.

In the present study, we aimed to characterize the role of DPP4 in fibroblast activation and tissue fibrosis. We demonstrate that 1.) DPP4 marks a population of activated fibroblasts, increased in SSc and in experimental fibrosis in a TGF- $\beta$ dependent manner; 2.) DPP4 regulates fibroblast activation and collagen release in vitro and in vivo; 3.) pharmacological inhibition of DPP4 with approved drugs induces regression of pre-established fibrosis in well tolerated doses, and 4.) despite consistent anti-inflammatory effects across different murine models, the anti-fibrotic effects are mainly mediated on DPP4 expression in tissue-resident cells such as fibroblasts.

This article is protected by copyright. All rights reserved. 


\section{Material and Methods}

\section{Additional, more detailed information on Material and methods can be found in the}

supplement of this manuscript.

\section{Patients and cells}

Skin biopsies were obtained and dermal fibroblasts were isolated from $23 \mathrm{SSc}$ patients and 21 healthy volunteers matched for sex and age. All SSc patients fulfilled the ACR/EULAR criteria for SSc (21). According to LeRoy classification of systemic sclerosis, 15 (65.2\%) patients were diffuse and $8(34.7 \%)$ patients belonged to the limited cutaneous subset of SSc. Sixteen patients were female, seven were male. The median age of patients with SSc was $52.7 \pm 12.3$ years (mean $\pm \mathrm{SD}$ ), and their median disease duration was $4.3 \pm 2.2$ years. 5 (21.7\%) patients were treated with immunosuppressive drugs at the time of biopsy (low dose steroids, methotrexate) or had received in the past cyclophosphamide or rituximab. All patients and healthy volunteers signed an informed consent approved by the local institutional review board.

Serum samples were collected from 50 SSc (53.8\% diffuse cutaneous SSc) patients fulfilling the ACR/EULAR criteria and 30 healthy controls. The median age of SSc patients was 55.6 \pm 13.4 years $($ mean \pm SD) with a mean disease duration of $7.2 \pm 3.4$ years (mean $\pm \mathrm{SD}) .11$ $(22,0 \%)$ patients were under treatment with immunosuppressive drugs.

In addition to human fibroblasts, murine fibroblasts were isolated from DPP4 knockout (DPP4-KO) mice and wildtype (WT) littermates (22).

This article is protected by copyright. All rights reserved. 


\section{Western blot analysis}

Proteins were separated by SDS-PAGE and transferred to a polyvinylidene difluoride membrane. The membranes were incubated with antibodies against SMAD3 (Santa Cruz Technologies, Heidelberg, Germany), pp44/p42 MAPK (Erk1/2), p44/p42 MAPK (Erk1/2), SAPK/JNK, pp38 MAPK. p38 MAPK, pAkt, Akt (pan), pNF-kB p65, NF-kB p65, pSRC (Cell Signaling, Boston, USA) or DPP4, pJnk (Abcam, Cambridge, UK) primary antibody and HRP-conjugated secondary antibodies (Dako, Hamburg, Germany). Blots were visualized by ECL. $\beta$-actin was used as loading control (23).

\section{Inhibition of canonical and non-canonical TGF- $\beta$ pathways}

To investigate the effect of TGF- $\beta$ non-canonical pathway on DPP4 expression, dermal fibroblast were incubated with the ERK inhibitor FR180204 $(10 \mu \mathrm{M})$ (Tocris Bioscience, Bristol, UK), the JNK inhibitor SP600125 (80 $\mu \mathrm{M})$ (Tocris Bioscience), the p38 inhibitor SP202190 $(1 \mu \mathrm{M})$ (Tocris Bioscience), the AKT inhibitor GSK690693 (0.1 $\mu \mathrm{M})$ (Tocris Bioscience), the SRC inhibitor SU6656 (500nM) (Tocris Bioscience), the NF-kB inhibitor

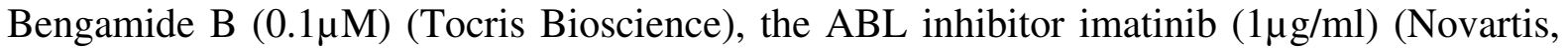
Basel, Switzerland), or the JAK inhibitor Ruxolitinib ( $5 \mu \mathrm{M})$ (LC Laboratories, Boston, USA) for 4 hours before stimulation with $\operatorname{TGF} \beta(10 \mathrm{ng} / \mathrm{ml})(24,25)$. To block the canonical pathway, SIS3 ( $3 \mu \mathrm{M}$, Sigma-Aldrich, Steinheim, Germany) was used. SD208 was used to inhibit the TGF- $\beta$ receptor I-kinase activity $(26,27)$. Total RNA was isolated with the NucleoSpin RNA II extraction system (Machery-Nagel, Düren, Germany) and reverse transcribed into complementary DNA (cDNA) with random hexamers.

This article is protected by copyright. All rights reserved. 


\section{Immunohistochemistry and immunofluorescence staining}

Formalin-fixed, paraffin-embedded human or murine skin sections or fibroblasts fixed in $4 \%$ PFA were stained with antibodies against aSMA (Life Technologies, Darmstadt, Germany), DPP4, vimentin or prolyl-4-hydroxidase, CD45, CD3 and B220 (all from Abcam), pERK (Cell Signaling). HRP-conjugated or Alexa Fluor antibodies (Life Technologies) were used as secondary antibodies. Irrelevant isotype matched antibodies served as controls (9). Nuclei were counterstained using DAPI (Santa Cruz). The staining was analyzed using a Nikon Eclipse 80i microscope (Nikon, Badhoevedorp, Netherlands).

\section{Mouse models of SSc}

\section{Bleomycin-induced skin fibrosis - preventive and therapeutic dosing}

DPP4-KO mice and wildtype (WT) littermates were injected subcutaneously with bleomycin or $0.9 \%$ sodium chloride $(\mathrm{NaCl})$, for four weeks $(28,29)$. Another group of mice was treated in parallel with the DPP4 inhibitor, Sitagliptin 10mg/kg (Selleckchem, Houston, USA), throughout the four weeks of bleomycin-challenge.

In the therapeutic, fibrosis was first induced by injection of bleomycin for three weeks (30). Thereafter, treatment with Sitagliptin $3 \mathrm{mg} / \mathrm{kg}$ and $10 \mathrm{mg} / \mathrm{kg}$ and Vildaglipin $1.5 \mathrm{mg}$ and $15 \mathrm{mg} / \mathrm{kg}$ (Biomol, Hamburg, Germany) was initiated for another three weeks, while mice were further challenged with bleomycin. The outcome was analyzed after six weeks after the first injection of bleomycin. Mice injected with $0.9 \%$ sodium chloride served as controls.

\section{Sclerodermatous chronic graft-versus-host disease (cGvHD)}

In the B10.D2 $\rightarrow$ Balb/c (H-2(d)) minor histocompatibility antigen-mismatched model, cGvHD was induced by allogeneic transplantation of $5 \times 10^{6}$ splenocytes and $1 \times 10^{6}$ bone marrow cells from B10.D2 mice into sub-lethally irradiated BALB/c $(\mathrm{H}-2 \mathrm{~d})$ mice. BALB/c 
(H-2d) mice transplanted with splenocytes and bone marrow cells isolated from BALB/c $(\mathrm{H}-$ 2d) mice served as controls $(31,32)$. Treatment started after appearance of first clinical signs of cGvHD at day 21 post transplantation, and the outcome was analyzed after six weeks.

\section{Bleomycin-induced pulmonary fibrosis}

DPP4-KO and WT mice were intratracheally injected with bleomycin or $0.9 \% \mathrm{NaCl}(27)$. Mice were sacrificed 4 weeks after injection. A subgroup of mice was treated with Sitagliptin in doses of $10 \mathrm{mg} / \mathrm{kg}$ from days 1 - 28 .

\section{Generation of bone marrow chimeric mice}

Mixed-bone marrow chimeras were generated by transplanting bone marrow from DPP4-KO mice into WT mice or vice versa. Before transplantation, recipient mice (DPP4-KO or WTmice) were sub-lethally irradiated (33). Bone marrow cells were isolated from tibial and femoral bones of DPP4 $\mathrm{KO}$ donor mice and injected into WT mice $(\mathrm{KO} \rightarrow \mathrm{WT}$ mice $)$ or DPP4-KO $(\mathrm{KO} \rightarrow \mathrm{KO})$. Similarly, bone marrow cells from WT mice were injected into DPP4-KO mice $(\mathrm{WT} \rightarrow \mathrm{KO})$ and into wildtype mice $(\mathrm{WT} \rightarrow \mathrm{WT})$. Fibrosis was induced by subcutaneous or intratracheal injections of bleomycin 10 days after bone marrow transplantation.

\section{Histological, biochemical and immunohistochemical analyses of the extent of fibrosis}

The extent of fibrosis was analyzed using histological, radiologic, biochemical, and immunohistochemical readouts. Histologic readouts included quantification of the dermal thickness on Hematoxylin Eosin (HE) stained sections at eight sites at 100-fold magnification (34), evaluation of the fibrotic area as percent of total lung area in Sirius Red stained sections (35); quantification of pulmonary changes using the Ashcroft score (36) and direct 
visualization of collagen by trichrome staining (27). The total collagen content was analyzed biochemically using hydroxyproline assays. In addition, myofibroblasts were identified immunohistochemically as $\alpha$-smooth muscle actin ( $\alpha$ SMA) positive.

\section{Statistics}

All data are presented as median \pm interquartile range, and differences between the groups were tested for their statistical significance by paired student t-tests for related samples and Mann-Whitney U non-parametric test for non-related samples. P-values less than 0.05 were considered significant. P-values are expressed as follows: $0.05>p>0.01$ as $* ; 0.01>p>$ 0.001 as $* * ; p<0.001$ as $* * *$.

\section{Results}

\section{DPP4 expression is increased in SSc fibroblasts}

We observed increased expression of DPP4 in the skin of SSc patients compared to matched healthy individuals (Fig. 1A). Co-staining with prolyl-4-hydroxylase- $\beta$ (P4H) demonstrated that fibroblasts express high levels of DDP4. DPP4 was also expressed in B and T cells of SSc patients, but fibroblasts were the dominant cell type expressing DPP4 in SSc skin (Suppl. Fig. 1). In SSc, $75.8 \%( \pm 7.8 \%)$ of P4H-positive fibroblasts were stained for DPP4, whereas only $29.1 \%( \pm 8.3 \%)$ of fibroblasts in healthy skin expressed DPP4 (Fig. 1A). Significantly more DPP4-positive fibroblasts co-expressed alpha smooth muscle actin ( $\alpha$ SMA) as compared to DPP4-negative fibroblasts, indicating that DPP4 marks a subpopulation of activated fibroblasts (Fig. 1B). We also observed increased expression of DPP4 in murine models of SSc such as bleomycin-induced skin fibrosis (Fig. 1C) and the B10.D2 (H-2 $)$

BALB/c $\left(\mathrm{H}-2^{\mathrm{d}}\right)$ model of sclerodermatous chronic graft versus host disease (cGvHD) with

This article is protected by copyright. All rights reserved. 
prominent staining of DPP4 in fibroblasts (Fig. 1C). Moreover, the protein level of DPP4 is elevated in SSc fibroblasts compared to dermal fibroblasts from healthy individuals (Fig. 1B). The levels of soluble DPP4 in the serum did not differ between patients with limited cutaneous and diffuse cutaneous SSc and healthy controls (Suppl. Fig. 2A). The enzymatic activity of DPP4 also did not differ between serum samples of SSc patients and controls.

\section{TGF- $\beta$ induces DPP4 expression in fibroblasts via ERK}

Incubation of normal human dermal fibroblasts with recombinant TGF- $\beta$ mimicked the DPP4 expression pattern of SSc fibroblasts with increased protein levels of DPP4 after 24 and $48 \mathrm{~h}$ (Fig. 2A), but normal mRNA levels (data not shown). We next analyzed, whether stimulation with TGF- $\beta$ may induce the enzymatic activity of DPP4 in human dermal fibroblasts. Indeed, stimulation of SSc fibroblasts with recombinant TGF- $\beta$ for 24 h upregulated DPP4 activity and this increase in activity correlated with the increase in DPP4 protein levels (Suppl. Fig. 2B). Consistent with the results in vitro, we observed increased expression of DPP4 in skin fibroblasts of mice with fibroblast-specific overexpression of a constitutively active TGF- $\beta$ receptor type 1 (TBR ${ }^{\text {act}}$ ) compared to control mice (Fig. 2A). Moreover, treatment of bleomycin-challenged mice with SD208, a specific inhibitor of the TGF- $\beta$ receptor I-kinase activity, prevented the bleomycin-induced upregulation of DPP4 protein (Fig. 2A). To identify which intracellular signaling cascades mediate the stabilization of DPP4 protein by TGF- $\beta$, we knocked down SMAD3 by siRNA in fibroblasts. However, knockdown of SMAD3 did not inhibit the stimulatory effects of TGF- $\beta$ on DPP4 expression (Fig. 2B). Comparable results were obtained by incubation with the SMAD inhibitor SIS3. We thus tested the role of various non-canonical TGF- $\beta$ pathways using specific inhibitors against various non-canonical intracellular mediators of TGF- $\beta$. Inhibition of ERK kinases ameliorated the stimulatory effects of TGF- $\beta$ on DPP4 expression, whereas inhibition of 
SRC, cABL, JAK, AKT, p38, NfאB and JNK did not interfere with TGF- $\beta$-induced DPP4 expression (Fig. 2C).

\section{DPP4 regulates fibroblast activation and collagen release}

To investigate the functional role of DPP4 in fibroblast activation, we first sorted DPP4expressing and DPP4-negative fibroblasts from the skin of mice (Suppl. Fig. 3A) and analyzed the transcription of key profibrotic genes. DPP4-expressing fibroblasts expressed higher levels of Collal, Colla2 and Acta2 mRNA (which encodes for aSMA) than DPP4negative fibroblasts. Similar results were obtained when DPP4-positive and DPP4-negative fibroblasts were isolated from the lungs (Suppl. Fig. 3B).

Further, we compared the fibrotic potential of fibroblasts isolated from DPP4-knockout mice (DPP4-KO fibroblasts) to that isolated from wildtype control littermates. DPP4-KO fibroblasts were less responsive to the stimulatory effects of TGF- $\beta$. Fibroblast-tomyofibroblast transition was impaired in DPP4-KO fibroblasts with reduced expression of $\alpha$ SMA and impaired formation of stress fibers upon stimulation with TGF- $\beta$ as compared to control fibroblasts (Fig. 3A). Moreover, TGF- $\beta$ failed to induce the mRNA levels of Collal, Colla2 and Acta2 or to increase the release of collagen in murine DPP4-KO fibroblasts (Fig. 3A). DPP4-KO fibroblasts also demonstrated delayed closure of the gap in scratch assays as compared to control fibroblasts (Suppl. Fig. 4). Consistently, treatment with the DPP4 inhibitor sitagliptin inhibited the stimulatory effects of TGF- $\beta$ on murine fibroblasts (Fig. $3 \mathrm{~A})$.

Overexpression of DPP4 in human fibroblasts increased the mRNA levels of ACTA2, COL1A1 and COL1A2 and the levels of collagen protein secreted into the supernatant (Suppl. Fig.5). Incubation of SSc fibroblasts with sitagliptin ameliorated TGF- $\beta$-induced fibroblast- 
to-myofibroblast transition, prevented upregulation of COL1A1 and COL1A2 mRNA by TGF- $\beta$ and reduced the release of collagen from human dermal fibroblasts (Fig. 3B).

We next aimed to characterize, how DPP4 inhibition interferes with TGF- $\beta$-induced fibroblast activation. We thus analyzed the effects of DPP4 inhibition on canonical and noncanonical TGF- $\beta$ pathways that have been implicated in the pathogenesis of fibrotic diseases. Treatment of human dermal fibroblasts with sitagliptin prevented the stimulatory effects of TGF- $\beta$ on ERK signaling leading to decreased levels of phosphorylated ERK (pERK) in human dermal fibroblasts (Fig. 3B). However, inhibition of DPP4 did not interfere with the TGF- $\beta$-induced SMAD3, STAT3, SRC, AKT signaling or with cJUN and FRA2 mediated AP1 signaling (Suppl. Fig. 6). Consistent results were also obtained in DPP4-KO cells (data not shown). Moreover, upon DPP4 overexpression levels of pERK increased, while pSMAD3 levels did not change, confirming the hypothesis that DPP4 exerts part of its effects via noncanonical TGF- $\beta$ signaling pathway (Suppl. Fig.7).

\section{DPP4-KO mice are protected from experimental dermal and pulmonary fibrosis}

To investigate whether the inhibitory effects of DPP4 inactivation on fibroblast activation in vitro translate into anti-fibrotic effects in vivo, we evaluated the role of genetic and pharmacological inactivation of DPP4 in bleomycin-induced pulmonary and dermal fibrosis. DPP4-KO mice appear phenotypically normal and the histological architecture of the lungs and the skin were not altered under homeostatic conditions (Fig. 4A). However, DPP4-KO mice were less sensitive to bleomycin-induced fibrosis. Pulmonary fibrosis induced by intratracheal injections of bleomycin was significantly ameliorated in DPP4-KO mice with reduced fibrotic area, decreased Ashcroft scores, less pronounced fibrotic changes on CT, reduced myofibroblast counts and decreased hydroxyproline content as compared to control littermates (Fig. 4A).

This article is protected by copyright. All rights reserved. 
DPP4-KO mice were also protected from skin fibrosis induced by subcutaneous injections of bleomycin with reduced dermal thickness, impaired myofibroblast differentiation and decreased hydroxyproline content (Fig. 4B).

In wildtype mice, preventive treatment with sitagliptin $10 \mathrm{mg} / \mathrm{kg}$, initiated together with the intratracheal or subcutaneous bleomycin-challenge, also improved all fibrotic readouts and strongly ameliorated bleomycin-induced pulmonary and dermal fibrosis. However, sitagliptin did not exert additional anti-fibrotic effects in DPP4-KO mice (Fig. 4), demonstrating that the anti-fibrotic effects of sitagliptin are indeed mediated by DPP4 inhibition and not by offtarget effects.

\section{Pharmacological inhibition of DPP4 induces regression of pre-established experimental}

\section{fibrosis}

Using a pharmacological approach in murine SSc models, we first employed the model of bleomycin-induced skin fibrosis. We did not use preventive dosing schedules, but started treatment with the DPP4 inhibitors sitagliptin and vildagliptin only after fibrosis has already been established (Fig. 5A). Both DPP4 inhibitors, in both doses strongly ameliorated bleomycin-induced dermal thickness, accumulation of myofibroblasts and the hydroxyproline content compared to vehicle-treated mice (Fig. 5A). DPP4 inhibition also induced regression of pre-established fibrosis when comparing to pre-treatment level (Fig. 5A). Further, consistent with the in vitro data, pERK expression was reduced upon treatment with DPP4 inhibitors in bleomycin challenged mice (Suppl. Fig. 8).

To further validate the anti-fibrotic effects of pharmacological DPP4-inhibition, we next analyzed the effects of sitagliptin and vildagliptin in the B10.D2 $\rightarrow$ Balb/c (H-2(d)) model of sclerodermatous cGvHD (Fig. 5B). Treatment with sitagliptin or vildagliptin, initiated after occurrence of first clinical signs, reduced cGvHD-induced dermal thickening, collagen 
deposition and myofibroblast differentiation (Fig. 5B). DDP4 inhibition also reduced the cGvHD-induced weight loss (Suppl. Fig. 9).

In addition to these two inflammation-driven models, we evaluated the antifibrotic effect of Sitagliptin in the Tsk-1 model of fibrosis as a less inflammation-dependent model of SSc. Sitagliptin significantly ameliorates fibrosis in Tsk-1 mice with reduced hypodermal thickness, myofibroblast count and hydroxyproline content as compared to vehicle-treated Tsk-1 mice. Treatment of Tsk-1 mice with Sitagliptin also significantly reduced the mRNA levels of Colla1, of Colla2 and of Acta2 (Suppl. Fig. 10).

\section{Anti-inflammatory effects of DPP4 inhibition}

DPP4 expression has been shown to be implicated in the regulation of $\mathrm{B}$ and $\mathrm{T}$ cell activity (37). Treatment with sitagliptin and vildagliptin decreased total leukocytes counts and reduced $\mathrm{B}$ and $\mathrm{T}$ cell numbers in the skin of mice with bleomycin-induced dermal fibrosis and with sclerodermatous cGvHD (Fig. 6A), demonstrating that DPP4 inhibitors also ameliorated inflammation in addition to its direct effects on fibroblasts.

We next aimed to characterize the contribution of DPP4 inactivation in leukocytes to the antifibrotic effects of DPP4 inhibition. Therefore, we generated chimeric mice by transplanting bone marrow from DPP4-KO mice in WT-littermates (DPP4-KO $\rightarrow$ WT mice with selective knockout of DPP4 in bone marrow derived cells such as leukocytes) and vice versa $(\mathrm{WT} \rightarrow \mathrm{DPP} 4-\mathrm{KO}$ mice with inactivation of resident, non-hematopoietic cells) (Fig. 6B) and induced fibrosis by intratracheal or subcutaneous injections of bleomycin, respectively. While the extent of pulmonary and dermal fibrosis of DPP4-KO $\rightarrow$ WT was comparable to that of $\mathrm{WT} \rightarrow \mathrm{WT}$ control mice, fibrosis was strongly ameliorated in WT $\rightarrow \mathrm{DPP} 4-\mathrm{KO}$ mice. Of note, all readouts of pulmonary and dermal fibrosis in $\mathrm{WT} \rightarrow \mathrm{DPP} 4-\mathrm{KO}$ mice were comparable to 
that of DPP4-KO $\rightarrow$ DPP4-KO mice (Fig. 6B and Suppl. Fig. 11), characterizing resident cells such as fibroblasts as major target cells for the anti-fibrotic effects of DPP4 inhibitors.

\section{Discussion}

We demonstrate in the present study that DPP4 expression is increased in SSc patients and in different murine models of skin fibrosis. We found no difference in the serum levels of DPP4 between healthy controls and SSc patients, as previously shown $(38,39)$, suggesting that DDP4 expression is regulated locally in fibrotic tissues. Although DPP4 is not specifically expressed in fibroblasts, co-staining with fibroblast markers demonstrated that fibroblasts are the predominant cell type expressing DPP4 in SSc skin and that the majority of SSc fibroblasts in situ are positive for DPP4. Of particular interest, we demonstrate that DPP4 expression marks a population of activated fibroblasts. DPP4-positive fibroblasts in SSc skin showed increased expression of prototypical myofibroblast marker $\alpha$ SMA compared to DPP4-negative cells. Moreover, dermal and pulmonary fibroblasts expressing DPP4 demonstrated increased transcription of type I collagens and Acta2 as compared to DPP4 negative fibroblasts from the same mice. A recent landmark study by Rinkevich et al. reported a DPP4-positive fibroblast population in embryonic skin that possess high fibroproliferative potential that expands upon tissue injury to promote wound healing (20). The findings of Rinkevich et al. and our results together suggest that a subpopulation of DPP4-positive fibroblasts expand to drive persistent tissue remodeling and tissue fibrosis in SSc. However, further studies with lineage tracing experiments are required to further confirm this conclusion.

We provide evidence that TGF- $\beta$ is a factor that may drive the expansion of DPP4-positive fibroblasts. We demonstrate on multiple experimental levels that non-canonical TGF- $\beta$ signaling is stimulating DPP4 expression: 1.) Stimulation of cultured dermal fibroblasts with 
recombinant TGF- $\beta$ upregulated the expression of DPP4 protein in normal dermal fibroblasts. 2.) DPP4 levels were increased in SSc fibroblasts as compared to fibroblasts isolated from healthy individuals. 3.) Overexpression of TBRI ${ }^{\text {act }}$ increases DPP4 expression in the skin of mice, thus confirming that TGF- $\beta$ is sufficient to increase DPP4 expression in fibroblasts in vitro and in vivo. 4.) Inhibition of the non-canonical TGF- $\beta$ signaling mediator ERK, inhibits the stimulatory effects of TGF- $\beta$ on DPP4 expression. 5.) Selective inhibition of TGF- $\beta$ signaling prevented the upregulation of DPP4 in experimental fibrosis, highlighting that TGF- $\beta$ signaling is required for the overexpression of DPP4 in experimental fibrosis.

The upregulation of DPP4 had direct functional consequences and promoted activation of certain non-canonical TGF- $\beta$ pathways in fibroblasts. Inactivation of DPP4 reduced the TGF$\beta$-induced activation of ERK signaling in cultured fibroblasts as well as experimental fibrosis. ERK is an important intracellular mediator of TGF- $\beta$, which is activated in SSc and targeted inhibition of ERK has been shown to ameliorate experimental fibrosis (40, 41). Other intracellular cascades regulated by TGF- $\beta$ were not affected by DPP4 inhibition. The molecular mechanisms underlying the selective regulation of ERK by DPP4 require further studies.

Consistent with the central role of TGF- $\beta$ signaling in fibrogenesis, the inhibitory effects of DPP4 on TGF- $\beta$ signaling directly translated into inhibition of fibroblast activation. Inactivation of DPP4 blocked TGF- $\beta$-induced fibroblast-to-myofibroblast differentiation and reduced the release of collagen in vitro. Genetic or pharmacologic inhibition of DPP4 also ameliorated experimental dermal and pulmonary fibrosis induced by bleomycin or by sclerodermatous cGvHD. Moreover, inactivation of DPP4 was shown to ameliorate CCL4induced liver fibrosis and cardiac remodeling after high-salt diet-induced heart failure (4244). Targeted inhibition of DPP4 was also shown to reduce scar formation after cutaneous wounds. The potent anti-fibrotic effects of DPP4 inhibitors may have direct translational 
implications: 1.) Pharmacologic inhibition of DPP4 did not only prevent further progression of fibrosis, but also induced regression of pre-established fibrosis to below pre-treatment levels. 2.) Potent anti-fibrotic effects were already observed with the lower doses of both DPP4 inhibitors in mice, implying that standard doses as used for the treatment of diabetes mellitus could be effective in fibrotic diseases such as SSc. 3.) Anti-fibrotic doses of DPP4 inhibitors are well tolerated and their application is not limited by adverse events in our preclinical models. 4.) DPP4 inhibitors are widely used for the treatment of diabetes, offering multiple drug candidates for further clinical studies.

We provide evidence that DPP4 inhibition does not only target fibroblast activation directly, but also reduces inflammation. Treatment with DPP4 inhibitors reduced leukocyte counts and in particular T cell and B cell infiltration in murine models of SSc; both of which are centrally involved in the pathogenesis of SSc $(1,45)$. Indeed, DPP4 has been shown to regulate Th2 polarization and regulate B cell activation (46-49). Despite potent effects on Band $\mathrm{T}$ cell infiltration into fibrotic tissues, our bone marrow transplantation experiments actually demonstrated that the pro-fibrotic effects of DPP4 predominantly required DPP4 expression in tissue resident cells such as fibroblasts.

DPP4 inhibitors are already in clinical use for the treatment of type 2 diabetes mellitus for more than 10 years. The adverse effects include in particular arthralgia or arthritis, but also hypersensitivity, skin-related reactions and pancreatitis. The Food and Drug Administration (FDA) released a warning in 2015 that DPP4 inhibitors may cause joint pain. However, different studies showed no increased risk of arthritis in patients treated with DPP4 inhibitors compared to other second-line antidiabetics. Postmarketing events of hypersensitivity reactions like anaphylaxis and angioedema have been reported in patients treated with DPP4 inhibitors. However, more detailed studies revealed a similar incidence of angioedema in 
patients treated with sitaglipin compared to placebo (50). Similar results were reported also for other DDP4 inhibitors such as saxagliptin.

In out experiments, mice treated with DDP4 inhibitors did not show evidence of adverse events on clinical monitoring or on necropsy, including no evidence of arthritis or angioedema.

In summary, we provide evidence that DPP4 characterizes a population of activated fibroblasts in SSc. However, DPP4 does not only serve as an activation marker, but is also functionally required for fibroblast activation and tissue fibrosis. Targeted inactivation of DPP4 exerted potent anti-fibrotic effects in different models of experimental dermal and pulmonary fibrosis. These results may have direct translational implications as DPP4 inhibitors are already in clinical use for diabetes.

\section{ACKKNOWLEDGEMENT}

We thank Vladyslav Fedorchenko, Regina Kleinlein, Katja Dreißigacker and Lena Summa for excellent technical assistance.

A.S. and A.M. received travel bursaries from the European League against Rheumatism (EULAR). A.S. was supported by an ARTICULUM fellowship for 12 months.

\section{CONTRIBUTIONS}

Alina Soare, 1a, 1b, 1c, 2, 3 Hermina A. Györfi, 1a, 2, 3, Alexandru E. Matei, 1a, 2, 3, Clara

Dees, 1a, 2, 3, Simon Rauber, 1a, 2, 3, Thomas Wohlfahrt, 1a, 2, 3, Chih-Wei Chen, 1a, 2, 3, Ingo Ludolph,1a, 2, 3, Raymund E. Horch,1a, 2, 3, Tobias Bäuerle,1a, 2, 3, Stephan von Hörsten, 1a, 2, 3, Carina Mihai, 1a, 2, 3, Oliver Distler, 1a, 2, 3, Andreas Ramming, 1a, 1c, 2, 3, Georg Schett,1a, 1c, 2, 3, Jörg H.W. Distler 1a, 1c,2, 3, 


\section{References}

1. Gabrielli A, Avvedimento EV, Krieg T. Scleroderma. The New England journal of medicine. 2009;360(19):1989-2003.

2. Ramming A, Dees C, Distler JH. From pathogenesis to therapy--Perspective on treatment strategies in fibrotic diseases. Pharmacological research. 2015;100:93-100.

3. Mizoguchi F, Slowikowski K, Wei K, Marshall JL, Rao DA, Chang SK, et al. Functionally distinct disease-associated fibroblast subsets in rheumatoid arthritis. Nature communications. 2018;9(1):789.

4. Crowley T, O'Neil JD, Adams H, Thomas AM, Filer A, Buckley CD, et al. Priming in response to pro-inflammatory cytokines is a feature of adult synovial but not dermal fibroblasts. Arthritis research \& therapy. 2017;19(1):35.

5. Filer A, Ward LSC, Kemble S, Davies CS, Munir H, Rogers R, et al. Identification of a transitional fibroblast function in very early rheumatoid arthritis. Annals of the rheumatic diseases. 2017;76(12):2105-12.

6. Buckley CD, Barone F, Nayar S, Benezech C, Caamano J. Stromal cells in chronic inflammation and tertiary lymphoid organ formation. Annual review of immunology. 2015;33:715-45.

7. Neumann E, Lefevre S, Zimmermann B, Gay S, Muller-Ladner U. Rheumatoid arthritis progression mediated by activated synovial fibroblasts. Trends in molecular medicine. 2010;16(10):458-68.

8. Sorrell JM, Caplan AI. Fibroblasts-a diverse population at the center of it all. International review of cell and molecular biology. 2009;276:161-214.

9. Palumbo-Zerr K, Soare A, Zerr P, Liebl A, Mancuso R, Tomcik M, et al. Composition of TWIST1 dimers regulates fibroblast activation and tissue fibrosis. Annals of the rheumatic diseases. 2017;76(1):244-51.

10. Gyorfi AH, Matei AE, Distler JHW. Targeting TGF-beta signaling for the treatment of fibrosis. Matrix biology : journal of the International Society for Matrix Biology. 2018.

11. Gorrell MD, Gysbers V, McCaughan GW. CD26: a multifunctional integral membrane and secreted protein of activated lymphocytes. Scandinavian journal of immunology. 2001;54(3):249-64.

12. Klemann C, Wagner L, Stephan M, von Horsten S. Cut to the chase: a review of CD26/dipeptidyl peptidase-4's (DPP4) entanglement in the immune system. Clinical and experimental immunology. 2016;185(1):1-21.

13. Mulvihill EE, Drucker DJ. Pharmacology, physiology, and mechanisms of action of dipeptidyl peptidase-4 inhibitors. Endocrine reviews. 2014;35(6):992-1019.

14. Kim HJ, Kwak WY, Min JP, Sung SY, Kim HD, Kim MK, et al. Dipeptidyl peptidase-4 inhibitor with beta-amino amide scaffold: synthesis, SAR and biological evaluation. Bioorganic \& medicinal chemistry letters. 2012;22(17):5545-9.

15. Dicker D. DPP-4 inhibitors: impact on glycemic control and cardiovascular risk factors. Diabetes care. 2011;34 Suppl 2:S276-8.

16. Lambeir AM, Durinx C, Scharpe S, De Meester I. Dipeptidyl-peptidase IV from bench to bedside: an update on structural properties, functions, and clinical aspects of the enzyme DPP IV. Critical reviews in clinical laboratory sciences. 2003;40(3):209-94.

17. Forssmann U, Stoetzer C, Stephan M, Kruschinski C, Skripuletz T, Schade J, et al. Inhibition of CD26/dipeptidyl peptidase IV enhances CCL11/eotaxin-mediated recruitment of eosinophils in vivo. Journal of immunology. 2008;181(2):1120-7.

18. Kameoka J, Tanaka T, Nojima Y, Schlossman SF, Morimoto C. Direct association of adenosine deaminase with a T cell activation antigen, CD26. Science. 1993;261(5120):466-9.

This article is protected by copyright. All rights reserved. 
19. Kim SC, Schneeweiss S, Glynn RJ, Doherty M, Goldfine AB, Solomon DH. Dipeptidyl peptidase- 4 inhibitors in type 2 diabetes may reduce the risk of autoimmune diseases: a population-based cohort study. Annals of the rheumatic diseases. 2015;74(11):1968-75.

20. Rinkevich Y, Walmsley GG, Hu MS, Maan ZN, Newman AM, Drukker M, et al. Skin fibrosis. Identification and isolation of a dermal lineage with intrinsic fibrogenic potential. Science. 2015;348(6232):aaa2151.

21. van den Hoogen F, Khanna D, Fransen J, Johnson SR, Baron M, Tyndall A, et al. 2013 classification criteria for systemic sclerosis: an American college of rheumatology/European league against rheumatism collaborative initiative. Annals of the rheumatic diseases. 2013;72(11):1747-55.

22. Marguet D, Baggio L, Kobayashi T, Bernard AM, Pierres M, Nielsen PF, et al. Enhanced insulin secretion and improved glucose tolerance in mice lacking CD26. Proceedings of the National Academy of Sciences of the United States of America. 2000;97(12):6874-9.

23. Liang R, Sumova B, Cordazzo C, Mallano T, Zhang Y, Wohlfahrt T, et al. The transcription factor GLI2 as a downstream mediator of transforming growth factor-betainduced fibroblast activation in SSc. Annals of the rheumatic diseases. 2017;76(4):756-64.

24. Chakraborty D, Sumova B, Mallano T, Chen CW, Distler A, Bergmann C, et al. Activation of STAT3 integrates common profibrotic pathways to promote fibroblast activation and tissue fibrosis. Nature communications. 2017;8(1):1130.

25. Matei AE, Beyer C, Gyorfi AH, Soare A, Chen CW, Dees C, et al. Protein kinases G are essential downstream mediators of the antifibrotic effects of sGC stimulators. Annals of the rheumatic diseases. 2018;77(3):459.

26. Uhl M, Aulwurm S, Wischhusen J, Weiler M, Ma JY, Almirez R, et al. SD-208, a novel transforming growth factor beta receptor I kinase inhibitor, inhibits growth and invasiveness and enhances immunogenicity of murine and human glioma cells in vitro and in vivo. Cancer research. 2004;64(21):7954-61.

27. Palumbo-Zerr K, Zerr P, Distler A, Fliehr J, Mancuso R, Huang J, et al. Orphan nuclear receptor NR4A1 regulates transforming growth factor-beta signaling and fibrosis. Nature medicine. 2015;21(2):150-8.

28. Distler A, Ziemer C, Beyer C, Lin NY, Chen CW, Palumbo-Zerr K, et al. Inactivation of evenness interrupted (EVI) reduces experimental fibrosis by combined inhibition of canonical and non-canonical Wnt signalling. Annals of the rheumatic diseases. 2014;73(3):624-7.

29. Zhang Y, Liang R, Chen CW, Mallano T, Dees C, Distler A, et al. JAK1-dependent transphosphorylation of JAK2 limits the antifibrotic effects of selective JAK2 inhibitors on long-term treatment. Annals of the rheumatic diseases. 2017;76(8):1467-75.

30. Soare A, Ramming A, Avouac J, Distler JH. Updates on animal models of systemic sclerosis. Jsrd. 2016;1(3):266-76.

31. Zerr P, Palumbo-Zerr K, Distler A, Tomcik M, Vollath S, Munoz LE, et al. Inhibition of hedgehog signaling for the treatment of murine sclerodermatous chronic graft-versus-host disease. Blood. 2012;120(14):2909-17.

32. Chen CW, Beyer C, Liu J, Maier C, Li C, Trinh-Minh T, et al. Pharmacological inhibition of porcupine induces regression of experimental skin fibrosis by targeting Wnt signalling. Annals of the rheumatic diseases. 2017;76(4):773-8.

33. Marquart S, Zerr P, Akhmetshina A, Palumbo K, Reich N, Tomcik M, et al. Inactivation of the cannabinoid receptor $\mathrm{CB} 1$ prevents leukocyte infiltration and experimental fibrosis. Arthritis and rheumatism. 2010;62(11):3467-76.

This article is protected by copyright. All rights reserved. 
34. Mallano T, Palumbo-Zerr K, Zerr P, Ramming A, Zeller B, Beyer C, et al. Activating transcription factor 3 regulates canonical TGFbeta signalling in systemic sclerosis. Annals of the rheumatic diseases. 2016;75(3):586-92.

35. Huang J, Beyer C, Palumbo-Zerr K, Zhang Y, Ramming A, Distler A, et al. Nintedanib inhibits fibroblast activation and ameliorates fibrosis in preclinical models of systemic sclerosis. Annals of the rheumatic diseases. 2016;75(5):883-90.

36. Hubner RH, Gitter W, El Mokhtari NE, Mathiak M, Both M, Bolte H, et al. Standardized quantification of pulmonary fibrosis in histological samples. BioTechniques. 2008;44(4):507-11, 14-7.

37. Waumans Y, Baerts L, Kehoe K, Lambeir AM, De Meester I. The Dipeptidyl Peptidase Family, Prolyl Oligopeptidase, and Prolyl Carboxypeptidase in the Immune System and Inflammatory Disease, Including Atherosclerosis. Frontiers in immunology. 2015;6:387.

38. Wronkowitz N, Gorgens SW, Romacho T, Villalobos LA, Sanchez-Ferrer CF, Peiro $\mathrm{C}$, et al. Soluble DPP4 induces inflammation and proliferation of human smooth muscle cells via protease-activated receptor 2. Biochimica et biophysica acta. 2014;1842(9):1613-21.

39. Sinnathurai P, Lau W, Vieira de Ribeiro AJ, Bachovchin WW, Englert H, Howe G, et al. Circulating fibroblast activation protein and dipeptidyl peptidase 4 in rheumatoid arthritis and systemic sclerosis. International journal of rheumatic diseases. 2018;21(11):1915-23.

40. Beyer C, Distler JH. Tyrosine kinase signaling in fibrotic disorders: Translation of basic research to human disease. Biochimica et biophysica acta. 2013;1832(7):897-904.

41. Skhirtladze C, Distler O, Dees C, Akhmetshina A, Busch N, Venalis P, et al. Src kinases in systemic sclerosis: central roles in fibroblast activation and in skin fibrosis. Arthritis and rheumatism. 2008;58(5):1475-84.

42. Kaji K, Yoshiji H, Ikenaka Y, Noguchi R, Aihara Y, Douhara A, et al. Dipeptidyl peptidase-4 inhibitor attenuates hepatic fibrosis via suppression of activated hepatic stellate cell in rats. Journal of gastroenterology. 2014;49(3):481-91.

43. Esposito G, Cappetta D, Russo R, Rivellino A, Ciuffreda LP, Roviezzo F, et al. Sitagliptin reduces inflammation, fibrosis and preserves diastolic function in a rat model of heart failure with preserved ejection fraction. British journal of pharmacology. 2017;174(22):4070-86.

44. Wang XM, Holz LE, Chowdhury S, Cordoba SP, Evans KA, Gall MG, et al. The profibrotic role of dipeptidyl peptidase 4 in carbon tetrachloride-induced experimental liver injury. Immunology and cell biology. 2017;95(5):443-53.

45. Wohlfahrt T, Usherenko S, Englbrecht M, Dees C, Weber S, Beyer C, et al. Type 2 innate lymphoid cell counts are increased in patients with systemic sclerosis and correlate with the extent of fibrosis. Annals of the rheumatic diseases. 2016;75(3):623-6.

46. Hatano R, Ohnuma K, Yamamoto J, Dang NH, Morimoto C. CD26-mediated costimulation in human $\mathrm{CD} 8(+) \mathrm{T}$ cells provokes effector function via pro-inflammatory cytokine production. Immunology. 2013;138(2):165-72.

47. Tasic T, Baumer W, Schmiedl A, Schwichtenhovel F, Pabst R, Raap U, et al. Dipeptidyl peptidase IV (DPP4) deficiency increases Th1-driven allergic contact dermatitis. Clinical and experimental allergy : journal of the British Society for Allergy and Clinical Immunology. 2011;41(8):1098-107.

48. Ohnuma K, Takahashi N, Yamochi T, Hosono O, Dang NH, Morimoto C. Role of CD26/dipeptidyl peptidase IV in human $\mathrm{T}$ cell activation and function. Frontiers in bioscience : a journal and virtual library. 2008;13:2299-310.

49. Yan S, Marguet D, Dobers J, Reutter W, Fan H. Deficiency of CD26 results in a change of cytokine and immunoglobulin secretion after stimulation by pokeweed mitogen. European journal of immunology. 2003;33(6):1519-27.

This article is protected by copyright. All rights reserved. 
50. Karagiannis T, Boura P, Tsapas A. Safety of dipeptidyl peptidase 4 inhibitors: a perspective review. Therapeutic advances in drug safety. 2014;5(3):138-46.

\section{Figure Legend}

Figure 1. DPP4 expression is increased in systemic sclerosis and murine models of SSc.

A Immunohistochemistry staining of DPP4 in skin of patients with SSc and healthy volunteers and immunofluorescence (IF) staining of DPP4 and $\mathrm{P} 4 \mathrm{H}$ and its quantification ( $\mathrm{n}=9$ for each). Representative images are shown at 200- and 600-fold magnification. B Expression of DPP4 in $\alpha$ SMA positive cells and quantification ( $\mathrm{n}=6$ for each). Representative images are shown at 400-fold. DPP4 protein in SSc and healthy skin analyzed by Western blot and its quantification ( $\mathrm{n}=6$ for each). C DPP4 expression in bleomycin-induced (bleo) skin fibrosis analyzed by IF microscopy and Western blot. Representative images are shown at 400 -fold ( $\mathrm{n}=5$ for each). DPP4 expression in murine fibroblasts of sclerodermatosus chronic graft versus host (cGvHD) disease model analyzed by IF microscopy and Western blot and its quantification ( $\mathrm{n}=5$ for each). Representative images are shown at 600-fold. Nuclei are stained with DAPI (blue). Results are shown as mean \pm SEM. ${ }^{*} p \leq 0.05$, $* * \mathrm{p} \leq 0.001, * * * \mathrm{p} \leq 0.0001$ as determined by Mann-Whitney test.

\section{Figure 2. Induction of DPP4 by TGF- $\beta$.}

A Expression of DPP4 upon stimulation with TGF- $\beta$ analyzed by Western blot and its quantification ( $\mathrm{n}=5$ for each). DPP4 protein level in murine skin overexpressing TGF- $\beta$ receptor type I (TBRI ${ }^{\text {act }}$ ) assessed by Western blot and its quantification ( $n=5$ for each). Effects of treatment with selective TBRI inhibitor SD208 on DPP4 protein level in bleomycin induced skin fibrosis analyzed by Western blot and its quantification ( $n=5$ for each). B Effect of SMAD3 knockdown on TGF- $\beta$ induced expression of DPP4 and its quantification ( $n=5$ for each). C TGF- $\beta$ induced DPP4 protein level upon inhibition of non-canonical TGF- $\beta$ pathway by SRC, ABL, JNK, JAK, NFאB, AKT, p38, ERK and SMAD inhibitors analyzed by Western blot and its quantification ( $\mathrm{n}=5$ for each). Inhibition of TGF- $\beta$ receptor I kinase activity with SD208 served as positive control. Results are shown as mean \pm SEM. ${ }^{*} \mathrm{p} \leq 0.05$, $* * \mathrm{p} \leq 0.001, * * * \mathrm{p} \leq 0.0001$ as determined by Mann-Whitney test.

\section{Figure 3. Inactivation of DPP4 inhibits fibroblast activation und collagen release.}

A Murine DPP4-KO fibroblasts: Representative images (shown at 200-fold magnification) and quantification of $\alpha \mathrm{SMA}$ and stress fibers in WT and DPP4-KO fibroblasts upon stimulation with TGF- $\beta$ ( $\mathrm{n}=5$ for each). Nuclei are stained with DAPI (blue). mRNA levels of Colla1, Colla2, Acta2 mRNA and collagen release in WT and DPP4-KO fibroblasts upon stimulation with TGF- $\beta$ ( $\mathrm{n}=5$ for each). Murine fibroblasts with pharmaceutical inhibition of DPP4: Colla1, Colla2, Acta2 mRNA levels and collagen release ( $\mathrm{n}=5$ for each). B Pharmacological inhibition of DPP4 in human dermal fibroblasts. Representative images (at 200-fold magnification) and quantification of $\alpha$ SMA and stress fibers in human dermal fibroblasts treated with sitagliptin upon TGF- $\beta$ stimulation $(\mathrm{n}=5$ for each). Treatment with Sitagliptin decreases the stimulatory effects of TGF- $\beta$ on COLlal and COLIa2 mRNA and 
decreases collagen protein release $(\mathrm{n}=8$ for each). Levels of phosphorylated ERK upon stimulation with TGF- $\beta$ and treatment with Sitagliptin analyzed by Western blot and its quantification ( $\mathrm{n}=5$ for each). Results are shown as mean $\pm \mathrm{SEM} .{ }^{*} \mathrm{p} \leq 0.05,{ }^{* *} \mathrm{p} \leq 0.001$, $* * * \mathrm{p} \leq 0.0001$ as determined by Mann-Whitney test.

Figure 4. DPP4-KO mice are partially protected from experimental bleomycin-induced pulmonary and dermal fibrosis.

A Bleomycin-induced pulmonary fibrosis: Representative images of Sirius Red, hematoxylin and eosin (HE)-stained sections (at 200-fold magnification) and high resolution computed tomography (CT) scans of the lungs. Quantification of the fibrotic area ( $\mathrm{n}=6$ for each), Ashcroft score ( $\mathrm{n}=6$ for each) and density quantification on CT in Hounsfield Units (HU) ( $n=6$ for each). Myofibroblast counts and ( $n=6$ for each) hydroxyproline content of the lung ( $\mathrm{n}=6$ for each). B Bleomycin-induced dermal fibrosis: Representative images of HEstained sections of the bleomycin-induced skin fibrosis mouse model shown at 200-fold magnification. Dermal thickness quantification ( $\mathrm{n}=8$ for each), myofibroblast count $(\mathrm{n}=8$ for each) and hydroxyproline content of the skin ( $n=8$ for each). Results are shown as mean \pm SEM. $\mathrm{p} \leq 0.05, * * \mathrm{p} \leq 0.001,{ }^{* * *} \mathrm{p} \leq 0.0001$ as determined by Mann-Whitney test.

Figure 5. Pharmacological inhibition of DPP4 induces the regression of bleomycin- and cGvHD-induced experimental fibrosis.

A Bleomycin-induced dermal fibrosis: Treatment scheme. Representative images of hematoxylin and eosin (HE) - stained sections of murine skin shown at 100 fold magnification ( $\mathrm{n}=6$ for each) and quantification of dermal thickness ( $\mathrm{n}=6$ for each), myofibroblast counts ( $n=6$ for each) and hydroxyproline content of the skin ( $n=6$ for each).

B Sclerodermatous cGvHD: Experimental outline. Representative images of HE-stained sections of murine skin shown at 100 fold magnification. Dermal thickness quantification ( $n=6$ for each), myofibroblast counts ( $n=6$ for each) and hydroxyproline content $(n=6$ for each). Results are shown as mean \pm SEM. ${ }^{*} p \leq 0.05,{ }^{*} p \leq 0.001, * * * p \leq 0.000$ as determined by Mann-Whitney test.

\section{Figure 6. Anti-inflammatory effects of DPP4 inhibition in the lung}

A Numbers of CD45, B220 and CD3 positive cells in bleomycin-challenged mice treated with DPP4 inhibitors ( $\mathrm{n}=6$ for each). Numbers of CD45 and B220 positive cells in cGvHD mice treated with DPP4 inhibitors. B Chimeric mice: Generation of mixed-bone marrow (BM) chimeras from DPP4 knockout or wildtype mice. Representative images of Sirius red staining, trichrome staining and high resolution computed tomography (CT) scans of the lungs of the chimeric mice ( $n=6$ for each). Quantification of the fibrotic area ( $n=6$ for each), Ashcroft score ( $\mathrm{n}=6$ for each) and fibrotic changes on CT-scans measured in Hounsfield Units (HU) ( $\mathrm{n}=6$ for each). Hydroxyproline quantification ( $\mathrm{n}=6$ for each) and myofibroblast counts $\left(\mathrm{n}=6\right.$ for each). Results are shown as mean \pm SEM. ${ }^{*} \mathrm{p} \leq 0.05, * * \mathrm{p} \leq 0.001,{ }^{* * *} \mathrm{p} \leq 0.000$ as determined by Mann-Whitney test.

This article is protected by copyright. All rights reserved. 
A
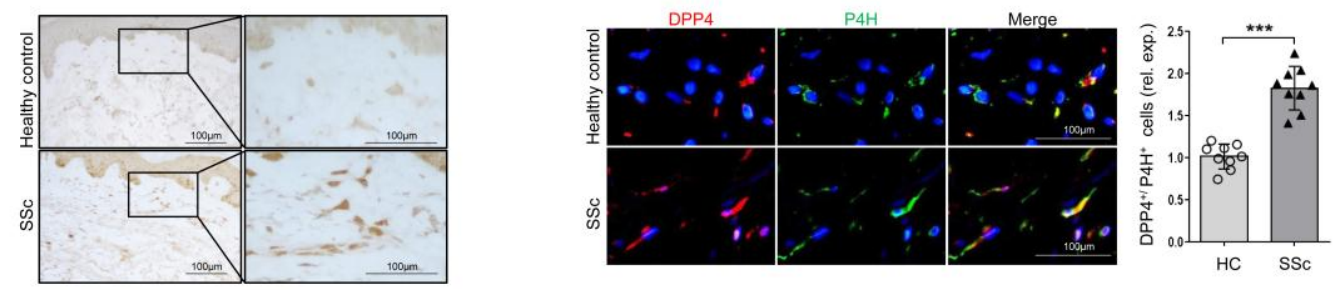

B
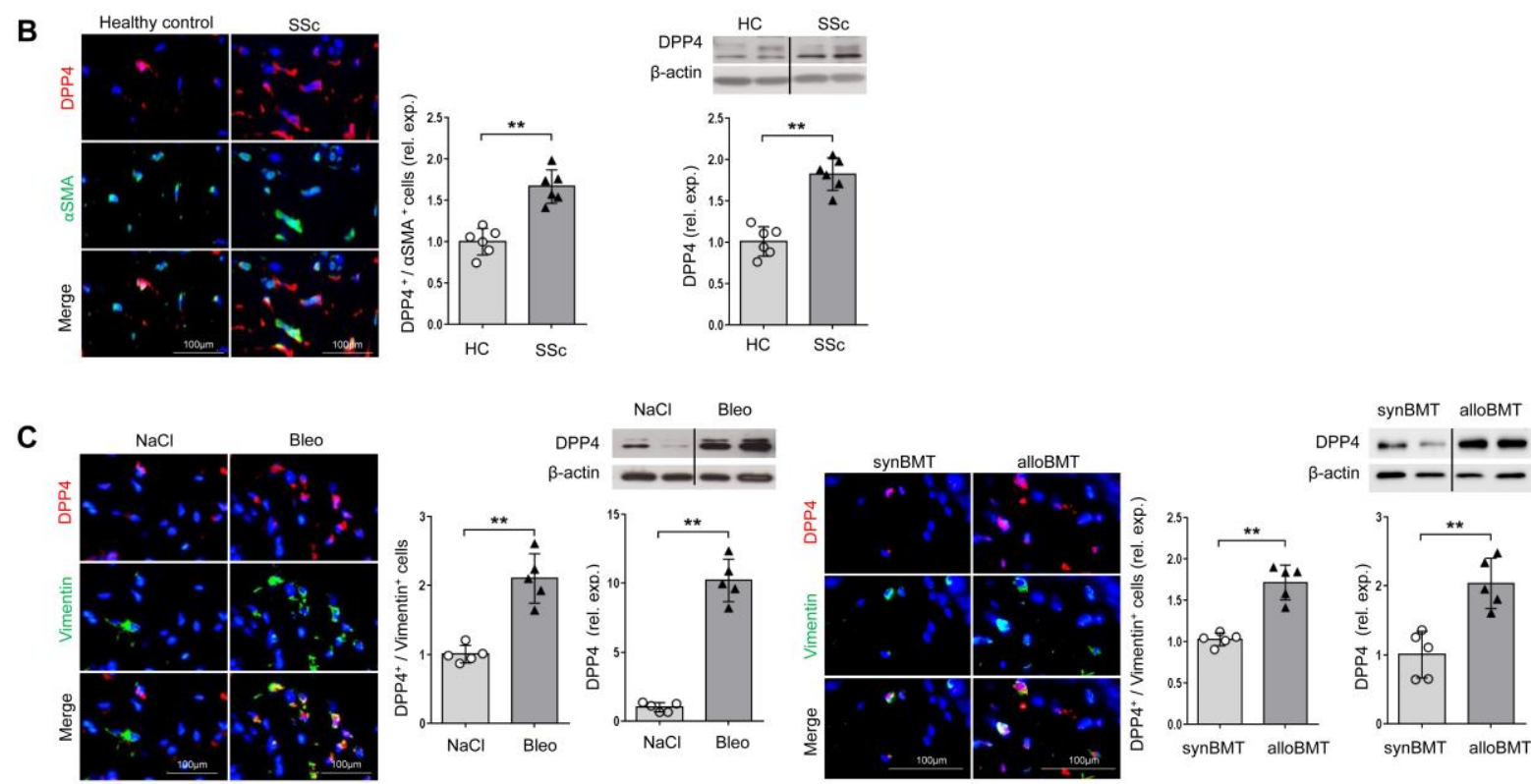

This article is protected by copyright. All rights reserved. 
A

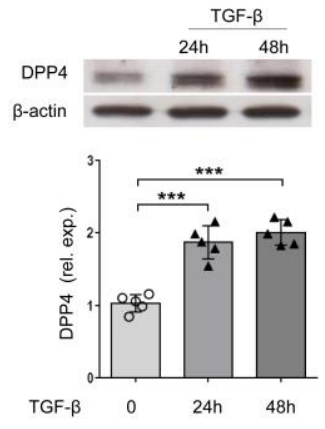

B

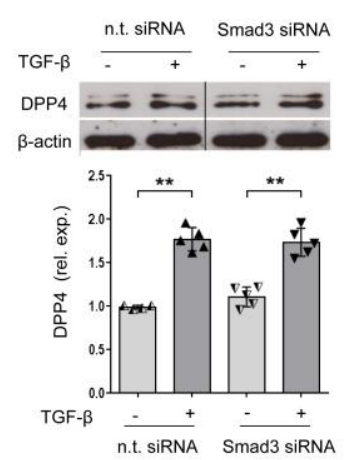

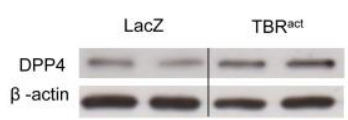

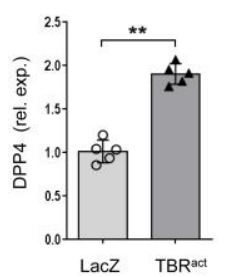

c

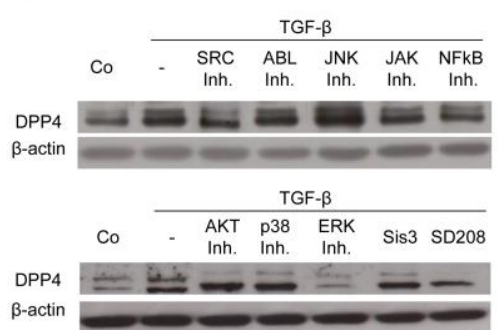

$\beta$-actin
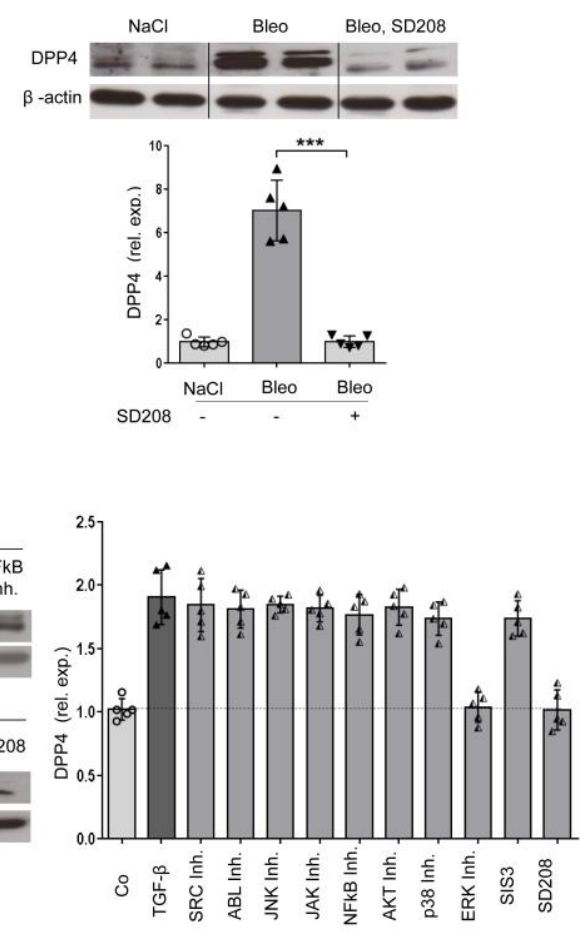

This article is protected by copyright. All rights reserved. 

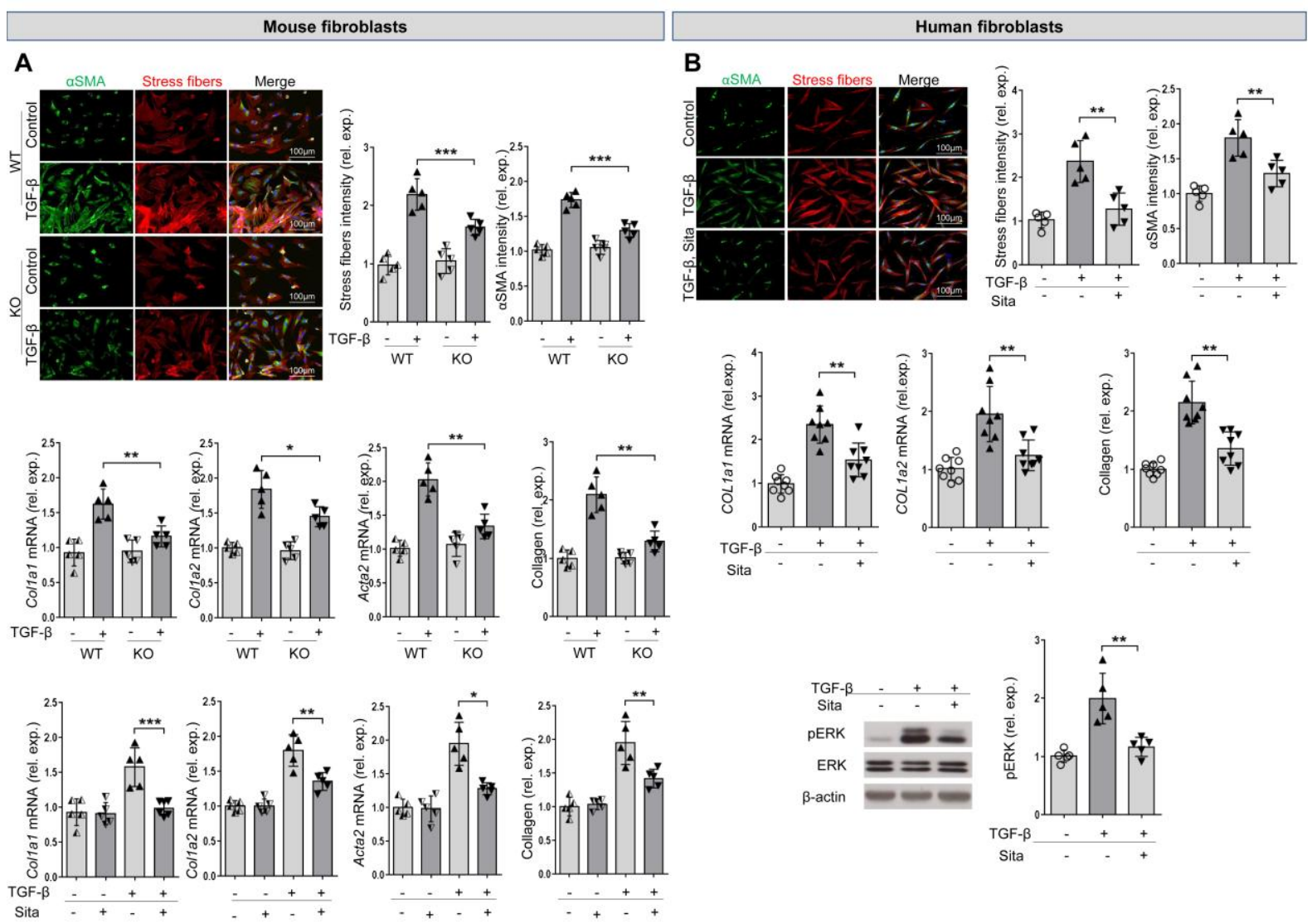


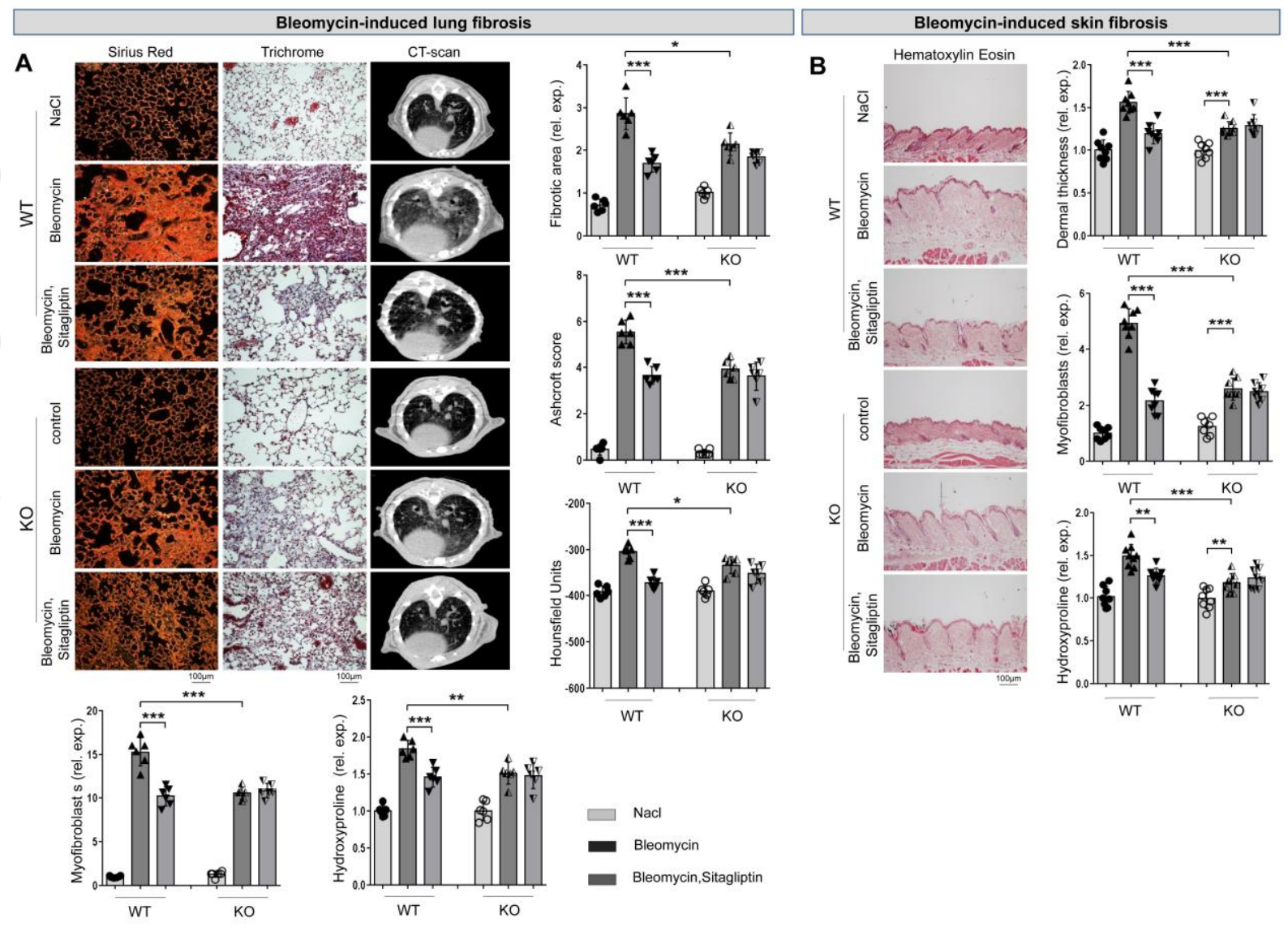

This article is protected by copyright. All rights reserved. 

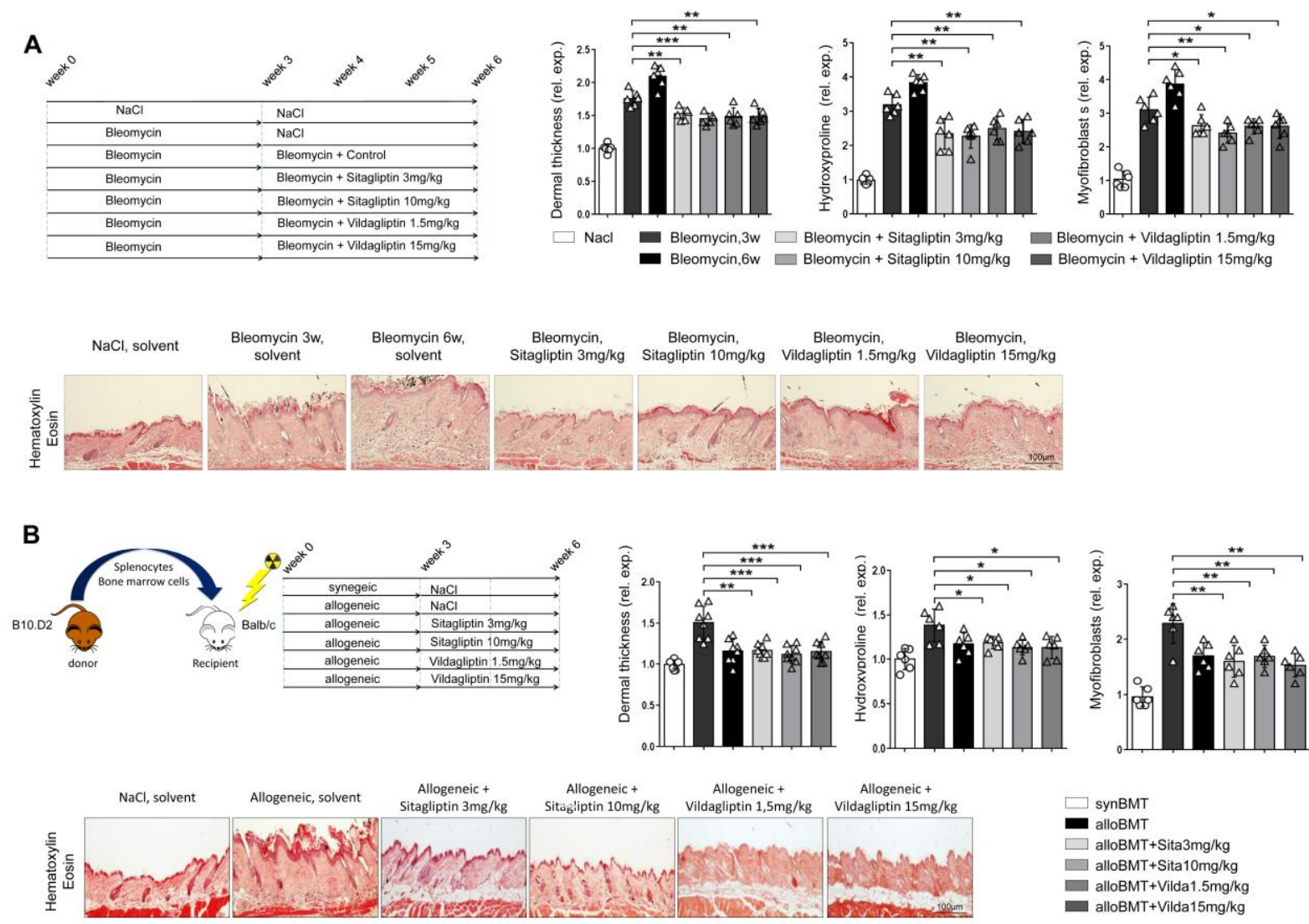

This article is protected by copyright. All rights reserved. 
A

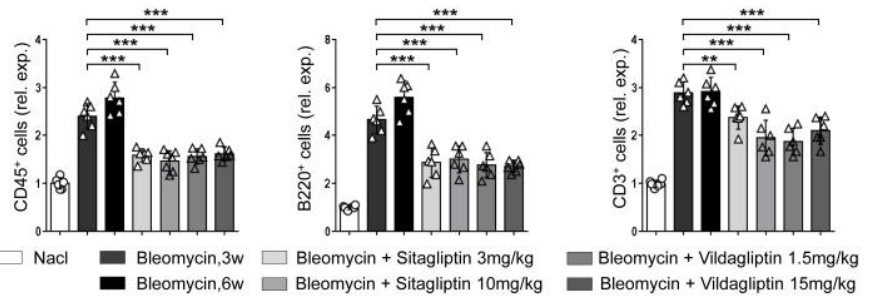

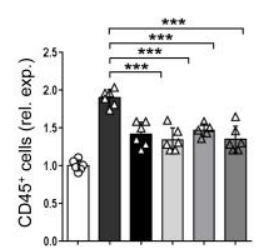

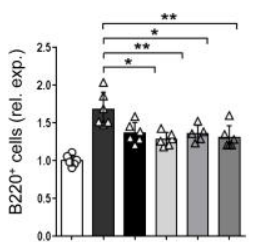

$\square$ synBMT $\square$ alloBMT+Sita $3 \mathrm{mg} / \mathrm{kg} \square$ alloBMT+Vilda $1,5 \mathrm{mg} / \mathrm{kg}$ alloBMT $\square$ alloBMT+Sita $10 \mathrm{mg} / \mathrm{kg}$ alloBMT+Vilda $15 \mathrm{mg} / \mathrm{kg}$

B
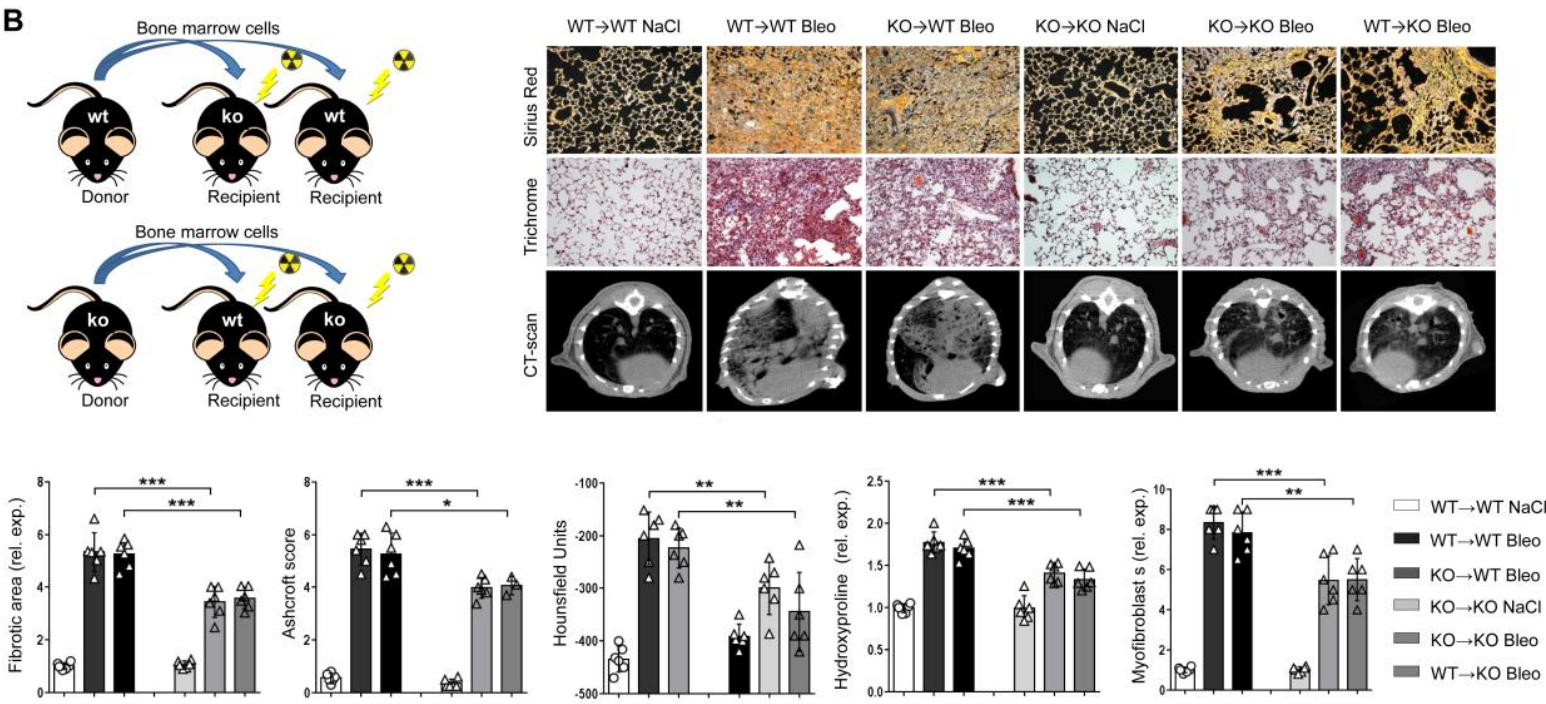

This article is protected by copyright. All rights reserved. 